\title{
Cognitive functions in schizophrenia: a comparative study in an Indian population
}

\author{
Kaberi Bhattacharyya, Prathama Guha, Malay Ghosal, Prabir Barman
}

\section{Background}

Significant cognitive impairment has been considered a core characteristic of schizophrenia. Though many studies have reviewed the phenomenon, only a few Indian studies have investigated this aspect.

Aims

To compare the functioning of six cognitive domains of patients with chronic schizophrenia with an age, sex and education matched control group and to assess the association of socio-demographic and clinical correlates with cognitive functioning.

Methods

Nine different neuropsychological tests were administered to assess the different cognitive domains. These were administered to 47 patients with chronic schizophrenia and 29 healthy controls. Results

Patients with schizophrenia performed poorly in the areas of processing speed, verbal learning, verbal working memory and visual working memory. We also found that negative symptoms predict poor performance in speed of processing and verbal working memory. Increased age was a predictor of better verbal fluency. Family history of schizophrenia in first degree relatives is a predictor of poor verbal working memory.

\section{Conclusions}

The findings suggest that patients with chronic schizophrenia show selective cognitive impairment. The study failed to show any impairment in the area of concentration and executive function, though patients needed more time and intermittent verbal prompts to reach a level of performance equivalent to controls. Negative symptoms were found to affect cognitive performance while age was associated with better verbal fluency performance.

SL J Psychiatry 2012; 3 (1):21-27

\section{Introduction}

Symptoms of schizophrenia can be categorized into the three domains of positive symptoms, negative symptoms and cognitive dysfunctions. Significant cognitive impairment has been considered a core characteristic of schizophrenia and is not caused by chronicity of illness, treatment or institutionalization (1). Whether the cognitive deficits in schizophrenia are better characterized as part of the generalized dysfunction or reflect relatively independent domain specific deficits is not yet known. Most studies report significant impairment in individual domains such as verbal memory and executive function, vigilance, memory and concept formation, working memory, learning, verbal memory and executive function $(2,3,4)$.

Impaired performance on neurocognitive tests correlates with deficits in everyday living and social outcomes across a number of neuropsychiatric conditions, particularly schizophrenia $(5,6,7,8,9)$. There has been some debate about whether the relationship between impairments in different cognitive domains and aspects of disability are specific or more generalized. For instance, in a study of people with schizophrenia, attentional performance was shown to predict early occupational success while sustained work performance was better predicted by episodic memory performance (10). In contrast, other studies have found correlations of essentially similar magnitude between multiple components of a cognitive assessment battery and various aspects of everyday functional outcomes
$(11,12)$. If the relationship between multiple cognitive impairments and different elements of functional disability are similar, then a detailed and lengthy neuropsychological assessment may not really be necessary. Based on this premise, several abbreviated cognitive assessment procedures have been developed $(13,14)$.

Only a few studies have examined cognitive impairment in Indian patients with schizophrenia. A study by Sabhesan and Parthasarthy in 2005 found varying degrees of executive function deficits in schizophrenia (15). Another study found that patients with stable schizophrenia performed poorly compared to euthymic bipolar affective disorder patients in the Wisconsin Card Sorting test, Continuous Performance Test and Spatial Working Memory Test (16). Two other studies have assessed the relationship between impaired cognitive function and functional disability of patients with schizophrenia $(17,18)$.

There is no brief neuropsychological assessment battery for schizophrenia which has been standardized for Indian patients. Indian studies conducted upto now tested specific cognitive domains in patients with schizophrenia using individual domain-specific tests and compared the performance with that of healthy controls.

In this study different test were assembled and used to measure different cognitive domains. These were based on the MCCB (MATRICS consensus cognitive 
battery). We have mostly used tests that have been already validated in Indian patients.

\section{Methods}

Objectives of the study were;

1. To compare functioning of six cognitive domains (speed of processing, attention/vigilance, verbal working memory, verbal learning, visual working memory, reasoning and problem solving) in patients with chronic schizophrenia with that of an age, sex and education matched control group.

2. To assess the correlation between demographic variables and clinical variables with functioning of different cognitive domains in patients with schizophrenia.

\section{Outcome measures}

Four original tests of the MCCB were replaced by similar tests already standardized for Indian populations. These were 1.Digit symbol subtest of WAPIS (Wechsler's adult performance intelligence scale) instead of BACS symbol coding 2. Verbal fluency subtest of KCSB (Kolkata Cognitive Screening Battery) for category fluency 3.Wordlist memory task subtest of KCSB in place of Hopkins verbal memory test 4. Visual retention subtest of PGI BBD (Post Graduate institute of India-Battery of Brain Dysfunction) for brief visuospatial memory test $(19,20,21,22)$.

The Adult Porteus Maze Test which is validated for Indian populations was selected instead of the Neuropsychological Assessment Battery (NAB) mazes test to test problem solving and reasoning. The Digit Cancellation Test (DCT) was selected to test attention instead of the Continuous Performance Test as some patients were not comfortable with using computers (23). This test has also been validated in adult Indians (24).

The final list of tests we used for assessing our subjects was as follows:

1. TMT (Trail making test)-Part-A. This tests visual scanning and visuomotor tracking which is a measure of speed of processing, measured in second (25).

2. Digit symbol subtest of WAPIS (Wechsler's adult performance intelligence scale). This measures speed of processing.

3. Verbal fluency subtest of KCSB (Koikata Cognitive Screening Battery, developed in Kolkata, WB, India). This measures speed of processing.

4. Word list memory task subtest of KCSB (immediate recall). This assesses verbal learning.

5. Spatial Span Subtest of WMS III (Wechsler Memory Scale) - This is the visual analog of digit span forward and backward. It assesses visual working memory (26).

6. Letter Number Sequencing (LNS) subtest of WMS III. This assesses verbal working memory.

7. Adult Porteus Mazes. A tests assessing reasoning and problem solving.
8. Visual retention subtest of PGI-BBD-(This is a neuropsychological battery developed in Post Graduate Institute, Chandigarh, India). It tests visual memory.

9. Digit cancellation test. This assesses attention.

All the above tests yield numerical scores. Higher scores indicate better cognitive functioning in all tests except TMT, Adult Porteus Maze and Digit cancellation test.

\section{Study population}

The study population consisted of consecutive patients diagnosed with schizophrenia, attending outpatient Psychiatry Department of Medical College and Hospital, Kolkata, India. Inclusion criteria were duration of illness more than 2 years, age between 1560 years, education above fifth standard and diagnosis made according to DSM IV TR using SCID I (Structured Clinical Interview for DSM VI TR). Age, sex and education matched healthy volunteers who didn't have any personal or family history of psychiatric illness were recruited as controls. Both cases and control were free from any major medical disorder such as diabetes, thyroid disorder. Sixty one patients were approached and 47 patients consented to take part in the study. Thirty two were males. Study was commenced after ethical clearance by the Institutional Review Board. Written informed consent was obtained using the informed consent form of ICMR from both patients and controls (27). Five patients refused to complete the digit cancellation test and appropriate statistical steps were taken to neutralize the deficiency.

\section{Statistical analysis}

To compare the performance in six cognitive domains in patients with chronic schizophrenia with those of an age, sex and education matched control group a preliminary Multivariate Analysis of Variance (MANOVA) analysis was done. Cognitive dysfunction measurements (CDM) of both cases and controls were used as dependent variables. The predictor variables included the demographic variables presence or absence of disease as well as the measurements of psychopathology of schizophrenia e.g. positive symptoms, negative symptoms, depressive symptoms. There were a total of twenty predictors. As the sample size was only 47 in the treatment group regression analysis was performed for each of the response variables in three steps. First a regression was done using all the predictor variables. Second a best subsets regression analysis was performed. This looks at all the possible models and the model with the smallest Cp value was selected as the "best model". Finally, a regression is carried out on the model selected by the Mallows' Cp criterion.

To assess the correlation between demographic and clinical variables and different cognitive domains in patients with schizophrenia, we carried out regression analyses for each of the response variables using only the data of patient group. 


Table 1-Socio demographic profile of cases and controls
\begin{tabular}{|ll|c|c|c|c|c|}
\hline Variables & Group & Number & Mean & SD & t -test & Significance \\
\hline Age (in years) & Cases & 47 & 35.70 & 11.0 & 0.914 & 0.364 \\
& Controls & 29 & 38.10 & 11.25 & & \\
Education (in years ) & Cases & 47 & 9.77 & 2.56 & 1.014 & 0.314 \\
& Controls & 29 & 10.38 & 2.55 & & \\
Per capita family income & Cases & 47 & 1742 & 2220 & 1.044 & 0.300 \\
(Indian Rupees) & Controls & 29 & 2400 & 3270 & & \\
\hline
\end{tabular}

\section{Results}

Demographic characteristics of study population The mean age of cases and controls were 35.70 years (SD 11.0) and 38.10 years (SD 11.25) respectively. The difference was not statistically significant $(\mathrm{p}=0.364)$ (Table 1). Among cases $68.1 \%$ were male and among controls $55.17 \%$ were males. T. The mean number of years of education was 9.77 (SD 2.56 ) in cases and in controls it was 10.38 (SD 2.55). Between group difference were not significant $(\mathrm{p}=0.314)$.

\section{Cognitive functions}

Cognitive functions (except "Digid cancellationwrong" and "Adult Porteus Mazes-error") were significantly poorer in patients with schizophrenia. Patients needed a longer time (213.7 seconds ) to complete the digit cancellation task compared to controls (172.6 seconds ). The mean time needed to complete the Adult Porteus Mazes was higher in patients with schizophrenia (40.7 seconds) compared to controls (30 seconds). Among the cognitive function measurements, the most difference between the patient and control groups were for $\mathrm{CCB}$ immediate recall $(t=4.87)$ and WMS $(t=5.043)$. Table 2 summarises the cognitive outcomes of the two groups.

\section{Identifying factors which predict cognitive functions:}

Stepwise regression analysis was carried out to find the relationship between socio-demographic variables and cognitive functions. Presence of disease was considered as one variable. The results are shown in table 3 .

Dependent variable TMT -the model selected included disease $(p<0.001)$, age $(p=0.014)$ and education $(p=0.067)$. Schizophrenia was associated with a significantly worse performance. Increased age was associated with better outcome for both groups.

Dependent variable digit symbol subtest of WAPISthe selected model included presence of disease $(p<0.001)$, age $(p=0.005)$ and education $(p=0.003)$.

\begin{tabular}{|c|c|c|c|c|c|c|c|}
\hline Variables & Group & Number & Mean & Median & SD & t-test & Significance \\
\hline TMT & $\begin{array}{l}\text { Controls } \\
\text { Cases }\end{array}$ & $\begin{array}{l}29 \\
47\end{array}$ & $\begin{array}{l}54.17 \\
78.94\end{array}$ & $\begin{array}{l}48.0 \\
73.0\end{array}$ & $\begin{array}{l}23.80 \\
32.96\end{array}$ & -3.516 & 0.001 \\
\hline WAPIS & $\begin{array}{l}\text { Controls } \\
\text { Cases }\end{array}$ & $\begin{array}{l}29 \\
47\end{array}$ & $\begin{array}{l}35.34 \\
24.45\end{array}$ & $\begin{array}{l}36.00 \\
23.00\end{array}$ & $\begin{array}{l}13.43 \\
10.55\end{array}$ & 3.937 & 0.000 \\
\hline CCB-immediate & $\begin{array}{l}\text { Controls } \\
\text { Cases }\end{array}$ & $\begin{array}{l}29 \\
47\end{array}$ & $\begin{array}{l}21.55 \\
17.79\end{array}$ & $\begin{array}{l}22.00 \\
17.00\end{array}$ & $\begin{array}{l}3.01 \\
3.43\end{array}$ & 4.870 & 0.000 \\
\hline WMS & $\begin{array}{l}\text { Controls } \\
\text { Cases }\end{array}$ & $\begin{array}{l}29 \\
47\end{array}$ & $\begin{array}{l}16.35 \\
11.40\end{array}$ & $\begin{array}{l}16.00 \\
12.00\end{array}$ & $\begin{array}{l}4.57 \\
3.87\end{array}$ & 5.043 & 0.000 \\
\hline LNS & $\begin{array}{l}\text { Controls } \\
\text { Cases }\end{array}$ & $\begin{array}{l}29 \\
47\end{array}$ & $\begin{array}{l}11.83 \\
8.00\end{array}$ & $\begin{array}{l}12.00 \\
9.00\end{array}$ & $\begin{array}{l}2.88 \\
4.92\end{array}$ & 3.800 & 0.000 \\
\hline $\begin{array}{l}\text { Adult Porteus } \\
\text { Mazes-number of } \\
\text { errors }\end{array}$ & $\begin{array}{l}\text { Controls } \\
\text { Cases }\end{array}$ & $\begin{array}{l}29 \\
47\end{array}$ & $\begin{array}{l}0.464 \\
1.436\end{array}$ & $\begin{array}{l}0.000 \\
1.000\end{array}$ & $\begin{array}{l}1.036 \\
1.790\end{array}$ & -2.62 & 0.011 \\
\hline PGIBBD & $\begin{array}{l}\text { Controls } \\
\text { Cases }\end{array}$ & $\begin{array}{l}29 \\
47\end{array}$ & $\begin{array}{l}11.04 \\
8.28\end{array}$ & $\begin{array}{l}12.00 \\
9.00\end{array}$ & $\begin{array}{l}2.30 \\
3.06\end{array}$ & 4.12 & 0.000 \\
\hline CCB-verbal & $\begin{array}{l}\text { Controls } \\
\text { Cases }\end{array}$ & $\begin{array}{l}29 \\
47\end{array}$ & $\begin{array}{l}44.39 \\
34.85\end{array}$ & $\begin{array}{l}42.50 \\
34.00\end{array}$ & $\begin{array}{l}9.66 \\
10.63\end{array}$ & 3.88 & 0.000 \\
\hline $\begin{array}{l}\text { Digit cancellation } \\
\text { test }\end{array}$ & $\begin{array}{l}\text { Controls } \\
\text { Cases }\end{array}$ & $\begin{array}{l}29 \\
47\end{array}$ & $\begin{array}{l}6.00 \\
16.67\end{array}$ & $\begin{array}{l}1.50 \\
5.00\end{array}$ & $\begin{array}{l}11.36 \\
26.53\end{array}$ & -2.00 & 0.049 \\
\hline
\end{tabular}




\begin{tabular}{|c|c|c|}
\hline Response & $\begin{array}{l}\text { Variables selected } \\
\text { (p-value) }\end{array}$ & $\begin{array}{l}\text { R-sq } \\
\text { (Adjusted } \\
\text { R-sq) }\end{array}$ \\
\hline TMT & $\begin{array}{l}\text { Disease }(0.00), \\
\text { Age }(0.014) \\
\text { Education }(0.066)\end{array}$ & $\begin{array}{l}24.3 \% \\
(21.1 \%)\end{array}$ \\
\hline WAPIS & $\begin{array}{l}\text { Disease }(0.00), \\
\text { Age }(0.005), \\
\text { Education }(0.003), \\
\text { Income }(0.06)\end{array}$ & $\begin{array}{l}38.9 \% \\
(35.5 \%)\end{array}$ \\
\hline $\begin{array}{l}\text { CCB-immediate } \\
\text { recall }\end{array}$ & Disease $(0.00)$ & $\begin{array}{l}24.3 \% \\
(23.2 \%)\end{array}$ \\
\hline WMS & $\begin{array}{l}\text { Disease }(0.00) \\
\text { Education (0.109) }\end{array}$ & $\begin{array}{l}28.2 \% \\
(26.2 \%)\end{array}$ \\
\hline LNS & $\begin{array}{l}\text { Disease }(0.00), \\
\text { Income }(0.028)\end{array}$ & $\begin{array}{l}21.7 \% \\
(19.6 \%)\end{array}$ \\
\hline $\begin{array}{l}\text { Adult Porteus } \\
\text { Mazes-number of } \\
\text { errors }\end{array}$ & $\begin{array}{l}\text { Disease }(0.015), \\
\text { Age }(0.147)\end{array}$ & $\begin{array}{l}11.2 \% \\
(8.8 \%)\end{array}$ \\
\hline PGIBBD & Disease $(0.00)$ & $\begin{array}{l}18.9 \% \\
(17.8 \%)\end{array}$ \\
\hline CCB-verbal & $\begin{array}{l}\text { Disease }(0.01), \\
\text { Age }(0.007), \\
\text { Sex }(0.125), \\
\text { Education }(0.158), \\
\text { Occupation }(0.111)\end{array}$ & $\begin{array}{l}33.1 \% \\
(28.3 \%)\end{array}$ \\
\hline $\begin{array}{l}\text { Digit cancellation } \\
\text { test-number of } \\
\text { errors }\end{array}$ & $\begin{array}{l}\text { Education }(0.104) \\
\text { Occupation }(0.05)\end{array}$ & $\begin{array}{l}9.3 \% \\
(6.6 \%)\end{array}$ \\
\hline
\end{tabular}

Patients with schizophrenia performed significantly worse compared to matched controls. Increased age and more years of education were associated with better performance in both groups.

Dependent variable immediate recall subtest of CCB- the selected model included only disease $(\mathrm{p}<0.001)$.

Dependent variable spatial span subtest of WMSthe selected model included disease $(p<0.001)$ and education $(p=0.109)$. Disease was a significant predictor of WMS.

Dependent variable LNS- the selected model included disease $(p<0.001)$ and income $(p=0.028)$. Higher per capita income was associated with better cognitive performance.

Dependent variable Adult Porteus Mazes-the selected model included disease $(\mathrm{p}=0.015)$ and age (0.147).

Dependent variable PGIBBD-The selected model included only disease $(p<0.001)$. Schizophrenia was a strong predictor of poor PGIBBD performance.

Dependent variable CCB-verbal- the selected model included disease $(p=0.01)$, age $(p=0.007)$, sex $(p=0.125)$, education $(p=0.158)$ and occupation $(0.11)$. Presence of disease and age were significant predictors. Increasing age was associated with better performance in the CCB verbal test.

Dependent variable digit cancellation- the selected model included education $(\mathrm{p}=0.104)$ and occupation $(\mathrm{p}=0.05)$. R-square and adjusted R-square values were low $(9.3 \%$ and $6.6 \%)$.

\begin{tabular}{|c|c|c|}
\hline Response & Variables selected ( $p$-value) & $\begin{array}{l}\text { R-sq } \\
\text { (Adjusted } \\
\text { R-sq) }\end{array}$ \\
\hline TMT & $\begin{array}{l}\text { PANSS-ve }(0.001), \\
\text { Family history }(0.009), \\
\text { Anergia }(0.019), \text { Sex }(0.074)\end{array}$ & $\begin{array}{l}24.3 \% \\
(21.1 \%)\end{array}$ \\
\hline WAPIS & $\begin{array}{l}\text { General } \\
\text { Psychopathology(0.003), } \\
\text { Sex (0.014), Activation(0.037) }\end{array}$ & $\begin{array}{l}38.9 \% \\
(35.5 \%)\end{array}$ \\
\hline $\begin{array}{l}\text { CCB- } \\
\text { immediate } \\
\text { recall }\end{array}$ & $\begin{array}{l}\text { PANSS+ve }(0.010), \\
\text { Education }(0.027), \text { Depression } \\
(0.105)\end{array}$ & $\begin{array}{l}24.3 \% \\
(23.2 \%)\end{array}$ \\
\hline WMS & 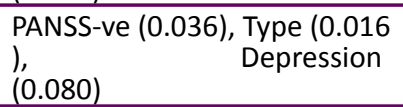 & $\begin{array}{l}28.2 \% \\
(26.2 \%)\end{array}$ \\
\hline LNS & $\begin{array}{l}\text { PANSS-ve(0.001), SUD(0.076), } \\
\text { family history }(0.001), \\
\text { Onset }(0.021), \text { Type }(0.004), \\
\text { Sex }(0.033)\end{array}$ & $\begin{array}{l}21.7 \% \\
(19.6 \%)\end{array}$ \\
\hline $\begin{array}{l}\text { Adult Porteus } \\
\text { Mazes- } \\
\text { number of } \\
\text { errors }\end{array}$ & PANSS-ve (0.091) & $\begin{array}{l}11.2 \% \\
(8.8 \%)\end{array}$ \\
\hline PGIBBD & $\begin{array}{l}\text { General } \\
\text { psychopathology(0.005) } \\
\text { Family history }(0.137)\end{array}$ & $\begin{array}{l}18.9 \% \\
(17.8 \%)\end{array}$ \\
\hline CCB-verbal & $\begin{array}{l}\text { Age }(0.001), \text { Sex }(0.066), \\
\text { Activation }(0.000), \\
\text { General psychopathology } \\
(0.001), \text { Occupation }(0.090)\end{array}$ & $\begin{array}{l}33.1 \% \\
(28.3 \%)\end{array}$ \\
\hline $\begin{array}{l}\text { Digit } \\
\text { cancellation } \\
\text { test-number } \\
\text { of errors }\end{array}$ & $\begin{array}{l}\text { General } \\
\text { psychopathology }(0.000) \text {, } \\
\text { F/HO(0.022), F/H1(0.023), } \\
\text { Activation (0.063) }\end{array}$ & $\begin{array}{l}9.3 \% \\
(6.6 \%)\end{array}$ \\
\hline
\end{tabular}

The above results indicate that the presence of disease predicted poorer performance in all cognitive function measurements except the DCT and Adult Porteus Mazes. Age was associated with better performance in TMT, digit symbol test (DST) and verbal fluency (VF). More years of education predicted better performance in DST and VF.

A regression analyses was then carried out on the treatment group. The variables included were clinical variables such as positive symptoms, negative symptoms, depressive symptoms and family history of schizophrenia. The positive and negative symptoms were determined using the Positive and Negative Syndrome Scale (PANSS). The results are shown in Table 4.

Dependent variable TMT- the selected model included negative symptom score $(\mathrm{p}=0.001)$, family history of schizophrenia $(p=0.009)$ and $\operatorname{sex}(p=0.074)$. High score on negative symptoms and family history of schizophrenia in first degree relatives were significant predictors.

Dependent variable WAPIS digit symbol-the selected model included only sex $(\mathrm{p}=0.014)$.

Dependent variable CCB immediate recall -Selected variables were positive symptom $\operatorname{score}(p=0.01)$, education $(p=0.027)$ and depression $(0.105)$. Higher scores on positive symptoms and lesser years of education were associated with poorer performance. 
Dependent variable WMS- the selected model included depression $(\mathrm{p}=0.08)$ and negative symptoms $(\mathrm{p}=0.036)$.

Dependent variable- LNS-the selected model included negative symptom score $(\mathrm{p}=0.001)$, family history of schizophrenia $(p=0.001)$, age of onset $(p=0.021)$ and sex $(p=0.033)$. Negative symptom score and family history of schizophrenia were significant predictors.

Dependent variable-Adult Porteus mazes- the selected model included only negative symptom score $(p=0.091)$. This was not a significant predictor.

Dependent variable- PGIBBD- the selected model included family history $(\mathrm{p}=0.137)$.

Dependent variable CCB-verbal- the selected model included age $(p=0.001)$, sex $(p=0.066)$ and occupation (0.09).Age was a significant predictor.

Dependent variable Digit cancellation test- the variable selected was family history $(\mathrm{p}=0.022)$.

The results suggest that negative symptom score predicted worse performance in speed of processing and verbal working memory. Age predicted performance on verbal fluency test. Schizophrenia in first degree relatives predicted poorer performance in verbal working memory.

\section{Discussion}

The main finding of the study was that patients with schizophrenia displayed significantly poorer performance in four cognitive areas but the difference was most distinct for immediate recall (verbal memory) and spatial span (visual working memory). Significant impairment in working and verbal memory in patients with schizophrenia has been reported previously. In particular the symbol coding task yields showed most impairment (28). Wexler et al. noted a general deficit in verbal memory despite normal motivation, attention and general perceptual function in a group of patients with schizophrenia. In the same study verbal working memory tasks were more impaired than nonverbal working memory tasks in patients with schizophrenia (29). This study, however, found greater deficits in nonverbal (visual) working memory. Similar findings were reported by Chey et al. who found that both immediate and visual memory task scores were poor in patients with schizophrenia (30). It thus appears that impairment in working memory in schizophrenia is a general deficit and not just confined to the verbal domain.

We found that increasing age was associated with better verbal fluency (semantic and categorical). This can be explained if schizophrenia is viewed as a neurodevelopmental disorder which actually remains stable or may even improve with time and this has been shown in several studies $(31,32)$. A meta- analysis of longitudinal studies of cognition in schizophrenia shows that semantic verbal fluency remains stable with age both in healthy controls and in patients with schizophrenia whereas other cognitive areas improve with age (33). Another meta-analysis shows that individuals with youth-onset schizophrenia have larger deficits in all areas of cognition whereas those with later onset disease has some relatively preserved cognitive function including vocabulary. This could either mean that patients with youth-onset schizophrenia are affected worse in terms of cognitive damage compared to the late onset group, or that increased age is associated with a richer vocabulary which provides some kind of compensation in cognitive testing (34).

This study failed to elicit any impairment in performances in the DCT (in its number of errors) in patients with schizophrenia. It has been reported that people with schizophrenia show greater distraction, slower response time, reduced vigilance and that they have problems with tasks requiring continual processing. They also have difficulties in distinguishing important stimuli from irrelevant stimuli and in multi-tasking as well as in maintaining or changing the location of attentional resources. In general, these attentional deficits come to the fore when tasks are very complex, as these require a higher degree of information processing (35). The absence of any impairment in this study may be due to the fact that the DCT task was an easier one. It was however noted that the patients needed a longer time (213.7 seconds) to complete the DCT task compared to controls (172.6 seconds). This is in keeping with findings reported by other authors (36).

This study showed no significant differences in the performances of the Adult Porteus Maze test between patients with schizophrenia and healthy participants as far as number of errors were concerned. The mean time needed to complete the Adult Porteus maze test was higher in patients with schizophrenia (40.7 seconds) compared to controls (30 seconds) and they responded better with intermittent verbal encouragement. Lis et al in 2003 also found that with feedback from previous actions, performance in patients with schizophrenia improved up to that of healthy individuals although they required a longer time (37).

Another important finding was that, among patients with schizophrenia, negative symptoms could significantly predict worse performance in terms of speed of processing and verbal working memory. In one study, patients with recent onset of schizophrenia were compared with age, sex and IQ matched healthy controls for different cognitive function and their relationship with symptoms of schizophrenia. An inverse relationship between speed of processing and negative symptoms was noted. On longitudinal follow up, impairment in the score of the digit symbol subtest was found to predict development or persistence of negative symptoms (38). In 2008 Rodriguez-Sanchez et al. analyzed the relationship between different cognitive tasks and disease symptoms (positive, negative and disorganized) in patients with first episode schizophrenia spectrum disorder. They found that negative symptoms were associated significantly with impaired executive function ( mainly speed of processing) and motor coordination tasks (39). Brebion et al. in 2009 found that depression, but not negative symptoms were associated with decreased processing speed in patients with schizophrenia (40). Working memory has often been considered to be an endophenotype of schizophrenia. Saperstein et al. conducted a study in 2006 to examine visuospatial working memory (SWM) as a cognitive endophenotype 
of schizophrenia by expanding the concept of risk for pathophysiological dysfunction beyond overt psychosis (41). Risk was defined by familial status and presence or absence of SSPD (schizophrenia spectrum personality disorder). SWM was assessed in patients with schizophrenia, SSPD relatives of patients with schizophrenia, non SSPD relatives of patients with schizophrenia, SSPD community members with no family history of psychosis and non SSPD community members. As expected, maximum deficits were found in the schizophrenia group. . Significant deficit were seen in the former two groups but not in patients with SSPD without a family history of psychosis (41). Ioana et al. also found working memory deficit in patients with a first episode of schizophrenia and their healthy siblings (42). This study found that a family history of schizophrenia was associated with a poorer verbal working memory among patients with schizophrenia; this is in keeping with findings in the existing literature.

Speed of processing, verbal learning, visual learning and working memory were impaired in patients with chronic schizophrenia when compared with the control group. The areas most impaired were immediate recall and visual working memory. Negative symptoms predicted worse performances in speed of processing and verbal working memory whereas increased age was associated with better verbal fluency. This study however, failed to analyse the patients' performance in terms of categorical and phonemic fluency separately, and instead considered verbal fluency as a single domain. As these two cognitive domains are controlled by different neural networks and appear to be affected differentially in patients with schizophrenia, this is a limitation of the study. Family history of schizophrenia was a predictor of greater impairment in verbal working memory. There was no impairment in concentration (digit cancellation test) and executive function (Adult Porteus Maze), though patients needed more time and intermittent verbal prompts to reach a level of performance equivalent to controls.

\section{Acknowledgement}

The assistance of Dr Utpal Dutta and Dr Dilip Mondal in conducting this study is gratefully acknowledged.

\section{Declaration of interest}

None

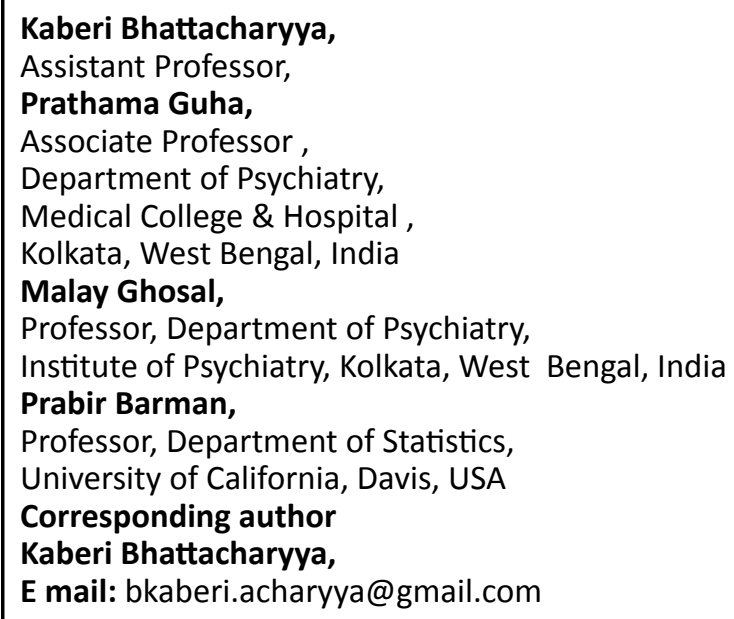

\section{References}

1. Mohamed S, Paulsen JS, Oleary D, Arndt S, Andreasen N. Generalized cognitive deficits in schizophrenia: A study of first episode patients .Arch Gen Psy 1999;56:749-54

2. Nestor P G, Kubicki M, Gurrera RJ, Niznikiewicz M, FruminM, McCarley RW, Shenton ME.. Neuropsychological correlates of diffusor tensor imaging in schizophrenia .Neuropsychology 2004 :18(4);629-637

3. Goldberg T E, Ragland JD, Torrey EF, Gold JM, Bigelow LB, Weinberger DR. Neuropsychological assessment of monozygotic twins discordant for schizophrenia Archives gen psy .1990;4:10661072

4. Saikin AJ, Gur RC, Gur RE, Mozley PG, Mozley LH, Resnick SM, Kester DB, Stafiniak P. .Neuropsychological function in schizophrenia. Selective impairment in memory and learning .Archives of gen psy .1991;48:618-624

5. Heaton $\mathrm{R} K$,Pendleton M G. Use of neuropsychological tests to predict adult patient's everyday functioning. Journal of consulting and clinical psychology.1981;49:807-821

6. Smith T E, Hull JW, Romanelli S, Fertuck E, Weiss KA.. Symptom of neurocognition as rate limiters in skill training for psychotic patients. AJP.1999; 156:1817-1818

7. Harvey P D, Howanitz E, Parrella M, White L, Davidson M, Mohs RC, Hoblin J, Davis KL. .Symptoms, cognitive functioning and adaptive skills in geriatric patients with lifelong schizophrenia :A comparison across treatment sites .A J P 1998 ; 155:1080-1086

8. Palmer B W, Heaton RK, Gladsio JA, Evans JD, Patterson TL, Golshan S, Jesty DV. Heterogeneity in functional status among older outpatients with schizophrenia: employment history, living situation and driving. Schizophrenia Research.2002;55:205-215

9. McGurk S R, Meltzer HY .The role of cognition in vocational functioning in schizophrenia .Schizophrenia Research .2000;45:175-184

10. Bryson G, Bell MD .Initial and final work performance in schizophrenia:cognitive and symptom predictors.Journal of nervous and mental diseases.2003;191:87-92

11. Evans J D, Heaton RK, Paulsen JS, Palmer BW, PattersonT, Jeste DV .The relationship of neuropsychologocal abilities to specific domains of functional capacity in older schizophrenic patients. Biological psychiatry .2003;53:422-430

12. McGurk S R, Mueser K T, Harvey P D, Puglia R L, Marder J..Cognitive and symptom predictors of work outcomes for clients with schizophrenia in supported employment. Psychiatric services . 2003;54:1129-1135

13. Keefe R S, Goldberg TE, Hervey PD, Gold JM, Poe MP, Coughnour L. .The brief assessment of cognition in schizophrenia: reliability Sensitivity and comparison with a standard neurocognitive battery.Schizophrenia research. 2004;68:283-297 
14. Velligan D I, DiCocco M, Bow-Thomas CC, Cadle C, Glahn DC, Miller AL, Biggs MM, ShoresWilson K, McKenzie CA, Crimson ML. .Abrief cognitive assessment for use with schizophrenia Patients in community clinics. Schizophrenia research .2004;71:273-283

15. Sabhesan $\mathrm{S}$, Parthasarathy S.executive functions in schizophrenia .IJP 2005;47:21-26

16. Trivedi J K, Goel D, Sharma S, Singh AP, Sinha PK, Tandon R. Cognitive function in stable schizophrenia and euthymic state of bipolar disorder.Indian journal of medical research.2007:126;433-439

17. Krishnadas R, Moore BP, Nayek A,Patel RR. Relationship of cognitive function in patients with schizophrenia in remission to disability:A cross sectional study in Indian sample.Annals of general psychiatry.2007:6;19

18. Srinivasan L, Tirupati S. Relationship between cognition and work functioning among patients with schizophrenia in an urban area of India. Psychiatric services,2005.56;1423-1428

19. Datta SGS, Pillai SV, Kovoor JME, Chandramouli BA. Post-concussion syndrome: Correlation of neuropsychological deficits, structural lesions on magnetic resonance imaging and symptoms. Neurology India 2009:57;5

20. 20.Wechler Adult Performance Intelligence Scale: Indian Adaptation of Wais a Performance Scale. Probha Ramalingaswami; Manasyan.1974

21. Das SK, Banerjee TK, Mukherjee PS, Bose P, Biswas A, Hazra A, Dutta A, Das S, Chowdhury A, Rout DK, Roy T. An urban community-based study of cognitive function among non demented elderly population of India. Neurology Asia 2006:11;37-48

22. Pershad D, 1990. Handbook of PGI battery of brain dysfunction. National psychological corpora,India

23. Sharma H, Sharma SK, Kadhiravan T, Mehta M, Sreenivas V, Gulati V, Sinha S. Pattern and correlates of neurocognitive dysfunction in Asian Indian adults with severe obstructive sleep apnoea. Indian J Med Res 2010:110;409-414

24. Barbhaiya HC, Desai RP, Saxena VS, Pravina K, Wasim P, Geetharani P, Allan JJ, Venkateshwarlu K, Amit A.Efficacy and tolerability of BacoMind on Memory Improvement in Elderly participants-A Double Blind Placebo Controlled Study. Journal of pharmacology and toxicology.2008;3(6) 425434

25. www.granddriver.net/data/media/docs/UIowa trailMaking.pdf

26. A compendium of neuropsychological tests:Administration, Norms and commentary, Third Edition.Strauss E et al.Oxford University Press, 2006

27. Ethical guidelines for biomedical research on human subjects. New Delhi: Indian Council for Medical Research; 2000

28. Bora E, Yusel M, Pantelis C Cognitive impairment in schizophrenia and affective Psychosis: Implication for DSM V criteria and beyond. Schizophrenia bulletin 2010;36(1):36-42

29. Wexler BE, Stevens AA ,Bowers AA ,Sernyak MJ ,Goldman-Racik. Word and tone working memory deficits in schizophrenia .Arch Gen Psy
1998;5:1093-1096

30. Chey J, Lee J, Kim YS, Kwon SM, Shin YM. Spatial working memory span,delayed response and executive function in schizophrenia. Psychiatry research 2002;110: 259-271

31. Delisi LE, Tew W, Xie SH, Hoff AL, Sakuma M, Kushner M, Lee G, Shedlack K,Smith AM, Grimson R.Aprospective follow up study of brain morphology and cognition in first episode schizophrenic patients: preliminary findings. Biol Psychiatry. 1995:38;349-60

32. Rund BR.A review of longitudinal studies of cognitive functions in schizophrenic patients.Schiz Bull.1998.24;425-35

33. Szoke A, Trandefir A, Dupont M E , Meary A, Schurhoff F, Leboyer M. Longitudinal studies of cognition in schizophrenia: A meta-analysis BJP 2008; 192:248-257

34. Rajji TK, Ismail Z, Mulsant BH,Age at onset and cognition in schizophrenia:A metanalysis.BJP 2009; 195:286-293

35. Balanzá, V. neurocognitiva en pacientes bipolares tipo I y esquizofrénicos (tesis doctoral). Valencia: Universitat de València. (2005) Estudio longitudinal de la función

36. Cullum CM, Harris JG, Waldo MC, Smernoff E, Madison A, Nagamoto HT, Griffith J, Adler LE, Freedman R. Neurophysiological and neuropsychological evidence for attentional dysfunction in schizophrenia. Schizophrenia Research. 1993:10(2);131-141

37. Lis S, Krieqer S, Wilhelm J, Galhofer B. Feedback about previous action improves executive functioning in schizophrenia: An analysis of maze solving behavior.Schizophrenia Research.2005:78(2);243-250

38. Leeson VC, Barnes TRE, Harrison M, Matheson E, Harrison I, Mutsatsa SH, Ron MA, Joyce EM. Tre relationship between IQ, memory, executive function, and processing speed in recent onset psychosis: 1 yr stability and course outcome. Schiz Bull.2008:36(2);400-409

39. Rodriguez-Sanchez JM, Crespo-Facorro B, Gonzalez-Blanch C, Perez-Iglesias R, AlvarezJimenez M, Martinez O, Vazquez-Barquero JL. Cognitive functioning and negative symptoms in First episode schizophrenia: different patterns of correlates. Neurotox Res 2008 Oct;14(2-3):227235

40. Brebion G, David AS,Jones HM, Pilowsky LS. working memory span and motor and cognitive speed in Schizophrenia. Cogn Behav Neurol 2009 Jun;22(2):101-8

41. Saperstein AM, Fuller RL, Avilla MT, Adami $\mathrm{H}$, McMahon RP, Thaker GK, Gold GM. Spatial working memory as a cognitive endophenotype of schizophrenia: Assessing risk for pathophysiological dysfunction Schiz Bull 32: 498-506

42. Ioana Miclutia,Codruta Popescu .Working memory in first episode schizophrenic patients and their healthy siblings. Journal of cognitive and behavioural psychotherapies 2008 18:17-30 